\title{
Avaliação educacional: para além da unilateralidade objetivista/subjetivista ${ }^{1}$
}

\author{
ZACARIAS GAMA*
}

\section{RESUMO}

O presente ensaio discute a unilateralidade objetivista e subjetivista que persiste na avaliação educacional e desenvolve argumentos favoráveis a uma nova forma de avaliar a aprendizagem dos estudantes da escola básica, considerando que as práticas objetivistas e subjetivistas são insuficientes em face de um projeto de uma sociedade emancipada. Com base teórica em autores marxistas, propóe uma prática de avaliação educacional com referência à objetividade social e subordina os instrumentos avaliativos de uso corrente a essa mesma objetividade.

Palavras-chave: avaliação da educação, avaliação da aprendizagem, ensino básico.

\section{RESUMEN}

El presente ensayo discute la unilateralidad del objetivismo y del subjetivismo que persiste en la evaluación educativa y desarrolla argumentos favorables a una nueva forma de evaluar el aprendizaje de los estudiantes de la escuela básica, considerando que las prácticas objetivistas y subjetivistas son insuficientes para un proyecto de sociedad emancipada. Basándose en autores marxistas, el trabajo propone una práctica de evaluación educativa con referencia a

\footnotetext{
${ }^{1}$ Devo a elaboração deste ensaio a dois amigos e colegas - Gaudêncio Frigotto e Marise Ramos - com os quais tenho o prazer de compartilhar aulas e momentos generosos de doação intelectual. Ao Gaudêncio agradeço a primeira leitura e as observações pontuais feitas com maestria e amizade.

* Professor Adjunto da Faculdade de Educação e do Programa de Pós-graduação em Políticas Públicas e Formação Humana (PPFH) da Universidade do Estado do Rio de Janeiro (UERJ) (zacarias_gama@yahoo.com.br).
} 
la objetividad social y subordina los instrumentos de evaluación de uso corriente a esa misma objetividad.

Palabras clave: evaluación de la educación, evaluación del aprendizaje, enseñanza básica.

\section{ABSTRACT}

The present essay discusses the objectivist and subjectivist unilateralism that persists in educational evaluation. It puts forward arguments favorable to a new form of evaluating the learning of basic school students and considers that the objectivist and subjectivist practices are insufficient regarding the project of an emancipated society. With a theoretical basis grounded in Marxist authors, it proposes an educational evaluation practice taking into account social objectivity and subordinates the evaluation instruments currently used to this same social objectivity.

Keywords: course evaluation, learning evaluation, basic education. 


\section{INTRODUÇÃO}

A avaliação educacional é central em minhas reflexôes há quase vinte anos. Durante essas duas décadas, estudei e refleti sobre como nós, professores, avaliamos a aprendizagem dos nossos estudantes; ajudei na proposição de novas formas de avaliar na reforma curricular "Núcleo Básico - Multieducação" para as escolas públicas da cidade do Rio de Janeiro; tentei compreender a continuidade de práticas avaliativas ultrapassadas em contextos de reformas educacionais; e detive-me na epistemologia dos discursos e enunciados avaliativos em circulação na WEB. Hoje, porém, estou convicto da necessidade de pensar a avaliação da aprendizagem na perspectiva da totalidade histórica, isto é, não como um todo já pronto e formalizado que determina as partes e sim como totalidade a ser construída historicamente, e cujo desenvolvimento "consiste justamente em submeter a si todos os elementos da sociedade” como assinala Kosik (1976). É nessa perspectiva que acredito ser possível superar a unilateralidade da avaliaçáo subjetivista e da avaliação objetivista, genericamente adjetivadas de avaliaçáo qualitativa e quantitativa. Obviamente, isso representa um grande desafio, porquanto inclui considerar ambas e atribuir à objetividade social o papel mais determinante, bem para além do simples objetivismo e do subjetivismo.

Este texto tem por objetivo argumentar em favor de uma nova forma de avaliar a aprendizagem dos estudantes da escola básica visando a superar as atuais práticas objetivistas e subjetivistas, todas criticáveis por serem insuficientes à formaçáo das novas geraçóes para uma sociedade emancipada. A exposição do texto constitui-se de dois momentos. No primeiro, discuto ser um contrassenso opor subjetividade à objetividade, ou qualidade a quantidade para, em seguida, examinar criticamente as práticas de avaliação fundadas no objetivismo e no subjetivismo. Detendome em uma e outra, procuro demonstrar suas contribuiçóes para as práticas de passividade, conformismo e reproduçáo social e o peso que o subjetivismo tem na desarticulação do processo social e em sua ênfase na afirmação de critérios individuais que engendram interpretações individualistas de mundo. No segundo momento, apresento o desafio de dar centralidade à objetividade nas práticas avaliativas e, sobretudo, na escola para a emancipação da sociedade. Mas, afinal, como se define esta objetividade e como pode se opor à unilateralidade objetivista/subjetivista? Esta é a discussão de fôlego. Esforço-me, então, para apresentar a objetividade pretendida como importante mediação, não apenas indispensável às práticas avaliativas, mas também para toda a escola e comunidade escolar. Nas consideraçóes finais, tento formular algumas táticas que podem levar à conquista de importantes posiçóes na escola. 
Como todo ensaio, este texto também não é um tratado formal e acabado. Está aberto ao debate e às críticas que possam aperfeiçoá-lo. Sua convicção mais concreta, porém, é a de tentar ir além das dicotomias recorrentes nas práticas avaliativas atuais em direção à realização da sociedade emancipada.

\section{SUBJETIVIDADE VERSUS OBJETIVIDADE: UM CONTRASSENSO}

Considero inicialmente um contrassenso opor subjetividade/objetividade ou qualidade/quantidade. Gramsci (1978), por exemplo, ao se debruçar sobre esta dicotomia, já demonstrou sua falsidade e ensinou-nos que a maneira mais concreta e realista de abordar o problema é "desenvolver a qualidade pelo único modo no qual tal desenvolvimento é controlável e mensurável”. Em sua perspectiva, a falsa oposição de uma a outra, implica "manter intactas determinadas condiçóes de vida social, nas quais alguns são pura quantidade; outros, pura qualidade”. Assim, considerar uma e outra numa interação complexa significa construir uma elaboração teórica que pretende apreender o movimento do real, isto é, da avaliação na sua totalidade. Esta é uma condição de superar as formas atuais que a avaliação adquire e, ao mesmo tempo, uma tentativa de contribuir para anular condiçóes de vida social que dáo mais valor ao trabalho intelectual, desqualificam o trabalho manual e reproduzem concretamente a divisão social do trabalho. Vejamos este ponto mais de perto.

Como sabemos, as teorias de avaliação não são neutras e sempre correspondem a diferentes concepçóes sociais de mundo. Cada classe cria sua concepção de mundo, mas é a da classe dominante que se torna hegemônica e é reproduzida constantemente.

A escola é uma instituição social. Mesmo que seja de direito privado atua sempre como aparelho de hegemonia de classe, uma vez que desempenha um papel ideológico e político importante para a unificação política de uma classe. Assim, por vezes, muitos professores, sem domínio consciente e coletivo da realidade concreta em sua totalidade, atuam no sentido de justificar, defender ou louvar o mundo da classe dominante, ainda que sua origem social seja diferente. Eles "proclamam como verdades eternas as concepçôes cotidianas" (Löwy, 2007) favoráveis à reprodução das relaçóes sociais em bases capitalistas. Em suas aulas restringem-se às aparências externas dos fenômenos, à superfície imediata das coisas. Seus pontos de vista, com raras exceções, são dogmáticos, sentenciosos e autoritários. É difícil dialogar com eles, porque não se dispóem a discutir as conexóes internas das relaçóes sociais e, menos ainda, a compreender e a admitir as contradiçóes da realidade. Suas fontes de informação, normalmente, são constituídas pelos jornais diários, revistas semanais 
de grande circulação e noticiários de televisão; é a partir delas que tendem a acomodar acriticamente os conteúdos disciplinares.

Para os docentes que se enquadram em tal descrição, a vontade e a ação humana são incapazes de interferir nas leis naturais que regem a sociedade. Eles acreditam que na vida social reina uma harmonia natural. Ao homem, cabe contemplar sem contestação esta harmonia e buscar as causas dos fenômenos "de forma objetiva, neutra, livre de julgamentos de valor ou ideologias, descartando previamente todas as prenoçóes e preconceitos" (Löwy, 2007). Da mesma forma, procuram estar blindados contra as ideias negativas, críticas e subversivas.

Auguste Comte (1990), fundador do positivismo, é o filosofo que está na base do sistema conceitual e axiológico que defende a ordem estabelecida e a avaliação em termos quantitativistas. Em sua perspectiva, "o fim essencial da política prática é, propriamente, evitar as revoluçôes violentas que nascem sobre obstáculos imaginários de quem se opóe à marcha da civilização”. E mais ainda: ele recomenda que "para alcançar este fim, é evidentemente indispensável conhecer, com a máxima precisão possível, a tendência atual da civilização, a fim de lhe conformar a ação política". É este mesmo filósofo que insiste na positividade das ciências naturais e presume serem elas que fornecem os métodos fundamentais para reorganizar a sociedade.

Michel Löwy, entretanto, faz duras críticas ao positivismo, a começar por ele não "ter intenção de buscar a verdade" e porque seu "discurso não tem conteúdo científico". A verdade com a qual trabalha, diz, faculta-lhe eliminar "os determinantes exteriores diretos, mas não o condicionamento estrutural (sociocultural)". Da mesma forma, permite-lhe tão somente "afastar a mistificação, mas náo o ponto de vista de classe".

\section{A AVALIAÇÃO OBJETIVISTA}

Concordando com as críticas de Löwy apresentadas acima, podemos afirmar que a teoria de avaliaçáo, produzida historicamente em consonância com os cânones do objetivismo, traduz-se na prática em processos que tendem a operar somente por meio de testes e outros instrumentos de apreciação do "status de um fenômeno de um modo preciso" como recomenda Popham (1978). Os testes e demais instrumentos avaliativos, por essa razão, são construídos com rigor científico para garantir o mínimo de distorçóes e o máximo de fidedignidade aos resultados. Sempre são considerados neutros, justos e sem contaminações subjetivas (assépticos, portanto). A preocupação com a objetividade é uma constante e opera para tornar real alguma 
coisa, torná-la típica da realidade objetiva, reificá-la, por conseguinte. A ideia é reduzir a subjetividade a critérios e a valores objetivos e, nessa direção, o processo de avaliação tenta atribuir alguma qualidade ao que é avaliado, independentemente do caráter ou índole do avaliador.

Vale ainda insistir que a avaliação objetivista corresponde à ideologia da classe dominante segundo a qual o mundo natural e social deixa de ser visto como histórico e resultante das atividades do homem. A este, aliás, somente lhe resta a contemplação, porquanto sua relação com o mundo é de exterioridade; cabe-lhe tão somente aceitar e admirar o que foi criado. Todo o seu conhecimento deve apenas permitir-lhe desvelar a verdade existente no mundo criado; seu conhecimento e sua ação devem ser regidos pela objetividade, entendida sempre como mundo real. No cotidiano escolar, tal teoria tem como escopo uma prática social que leva o estudante a atitudes de passividade e conformismo diante do mundo, que lhe interdita atividades de transformaçáo social. Adaptar os estudantes a uma ordem cósmica inalterável em sua natureza é o que compete ao professores que se alinham à ideologia positivista, a essa concepção social de mundo.

O problema central que as práticas de avaliação fundamentadas na objetividade apresentam é a inculcação da concepção social de mundo da classe dominante e sua efetiva reprodução. Por essa razão elas, sem dúvida, devem ser desprezadas. Contudo, seus instrumentos formais para exames - provas, exercícios etc. -, desenvolvidos com base no objetivismo, desde que mediados pela objetividade social que aqui estamos ensaiando, não são desprezíveis. Eles podem ser eficazes para diagnosticar os níveis reais e potenciais dos estudantes, porém, jamais para classificá-los ou excluí-los do sistema de ensino. Eles ainda mostram que conhecimentos os estudantes apreenderam e em quais precisam de ajuda. Isto é, eles apontam qual o potencial dos estudantes para novos e mais complexos desafios e seu grau de autonomia, bem como identificam pontualmente onde novas mediações de ensino/aprendizagem são indispensáveis.

É deste modo, e somente deste, que se tornam úteis para os nossos fins os instrumentos avaliativos produzidos em bases objetivistas.

\section{A AVALIAÇÃO SUBJETIVISTA}

A teoria de avaliação fundada historicamente no subjetivismo cria possibilidades práticas bem diferentes ao atribuir ao sujeito outra situação diante do mundo. Se antes ele é considerado um ser passivo, agora é tido como ativo e reconhece-se a importância da atividade humana, tanto em termos de conhecimento como de 
construção da realidade social. A subjetividade humana em seus limites é importante mediação para a articulação do mundo. Não por acaso, tal teoria avaliacional desloca a ênfase dos produtos escolares para os processos, e o estudante é colocado no centro dinâmico do processo de ensino e aprendizagem.

Tonet (2005, p. 46) indica-nos que "hoje vigora não apenas a centralidade, mas a hipersensibilidade da subjetividade, que se manifesta sob as mais diversas formas e nas mais variadas áreas". O irracionalismo, o neoiluminismo e o pragmatismo dos dias atuais são escolas de pensamento que enfatizam a subjetividade em detrimento da objetividade que se recusa à compreensão. A crítica de Tonet a esse respeito é contundente. Alega que um resultado imediatamente visível de tal centralidade na subjetividade é a produção de um "espírito de superficialidade" manifesto no consumo de modas teóricas, na ausência de seriedade, na despreocupação com uma fundamentação rigorosa, na utilização pouco criteriosa de diversos conceitos. Outro resultado é a rejeição da perspectiva histórico-ontológica "que compreende tanto a realidade objetiva quanto o conhecimento como resultados da práxis humana”, e cujo efeito é a afirmação da incapacidade do homem de entender a realidade como totalidade e, por consequência, a impossibilidade de intervir para transformá-la radicalmente.

No perímetro estrito das práticas avaliativas subjetivistas, as valorizaçóes da consciência, das ideias e das vontades dos estudantes têm levado os avaliadores e os seus instrumentos de avaliação a se abrirem às representaçôes que os estudantes fazem da realidade objetiva, mesmo sabendo-se a priori serem produzidas conforme suas experiências sociais, e que somente existem em suas mentes. $\mathrm{O}$ efeito é a verdade ceder lugar a diversas verdades, assim como a História, às histórias; o gênero humano, a grupos sociais diferentes e a indivíduos singulares. Perde-se definitivamente o fio condutor que articula todo o processo social e, por conseguinte, a autoconstruçáo do homem pelo homem, em favor de uma interpretação de mundo segundo critérios individuais, fragmentados, portanto.

Tais práticas avaliativas, nestas bases, expressam determinada realidade social objetiva, na qual os laços sociais são afrouxados. Sennet (2007) define esta realidade de "capitalismo de curto prazo" e identifica-a como responsável pela corrosão das qualidades de caráter que ligam os homens uns aos outros, dando a cada um deles "um senso de identidade sustentável". Nela, diz mais, as relaçóes familiares são profundamente alteradas pelos comportamentos imediatistas, de curto prazo, assim como é cada vez maior a fraqueza da lealdade, do compromisso mútuo, da confiança no outro, do senso objetivo. 
Por essas razóes, uma nova teoria avaliacional deve ultrapassar a dicotomia objetivista-subjetivista, bem como a centralidade, ora na objetividade, ora na subjetividade, e suplantar de vez a unilateralidade que impóem. O desafio, deste modo, está no resgate e na reformulação da centralidade da objetividade da classe dominada; como vencer tal desafio é a questão imperiosa.

Antes, porém, é necessário examinar os instrumentos avaliativos produzidos em bases subjetivistas. No jargão pedagógico, eles compreendem as chamadas provas, testes e questóes abertas, isto é, instrumentos de avaliação nos quais há espaços para as dissertaçôes, descrições etc. Mas como são espaços abertos às representações da realidade objetiva conforme as experiências sociais e a imaginação dos estudantes, como já vimos, prestam-se apenas à reprodução das diversas verdades, do relativismo que instaura o império das histórias particulares, dos grupos sociais diferentes e dos indivíduos singulares. A totalidade concreta cede lugar à fragmentação. A mediação da objetividade, porém, pode atribuir novo significado a tais instrumentos de modo que se tornem espaços abertos nos quais se busca ir além do parcial, estabelecer ligações e vislumbrar perspectivas, "conseguindo como conjuntos a situação, a comunidade e até o desenrolar da História”, como nos ensina Snyders (1993).

\section{OBJETIVIDADE NA AVALIAÇÃO EDUCACIONAL: O DESAFIO}

A centralidade da objetividade na avaliação que estou ensaiando está, neste caso, para além do simples afastamento dos preconceitos e das pressuposiçóes, da separação dos julgamentos de fato dos julgamentos de valor, da superação de antigos ideais de neutralidade, como os dos físicos, por exemplo, defendidos como indispensáveis à Sociologia, História, enfim, às Ciências Sociais.

Meu ponto de partida admite que a avaliação como prática social concreta deva estar a serviço da autoconstrução do homem emancipado, mas jamais a partir de posiçóes idealistas que incitam os professores, individual ou coletivamente, a agir no sentido da transformação social, sem haver efetivas condições de trabalho. $\mathrm{O}$ exemplo do professor do filme "A Sociedade dos Poetas Mortos" (A Sociedade..., 1989) esclarece o que digo e ajuda a fugir do idealismo. Ele, um romântico professor de literatura, sem conhecimento da realidade concreta onde ia atuar, tenta revolucionar os métodos de ensino propondo que seus alunos aprendessem a pensar por si mesmos e aproveitassem os momentos de prazer imediato, carpe diem sem medo do futuro. $\mathrm{O}$ final do filme, como se sabe, não poderia ser diferente: um dos estudantes suicida-se pois não atingiu o nível de maturidade para resolver seus problemas existenciais, o professor é sumariamente demitido, e o ano letivo seguinte recomeça nas 
mesmas bases conservadoras de sempre. A imaginação empolgada dos românticos, afinal de contas, sobrepóe-se ao real e os leva a viver o exagero de suas fantasias, sem medir as consequências para si e para os outros.

O imperativo é, pois, conhecer o real, visto que "a realidade concreta estabelece, ela mesma, um campo de possibilidades, que náo são nem infinitas e nem sequer muito grandes". Isto, todavia, demanda que os sujeitos envolvidos nos processos escolares de ensino, aprendizagem e avaliação tenham domínio consciente e coletivo da realidade concreta em sua totalidade. Todos precisam conhecer os indivíduos históricos que dão vida ao cotidiano escolar, quais relaçôes estabelecem entre si, como se desenvolvem realmente em meio às determinaçôes empiricamente visíveis. $\mathrm{O}$ mesmo ocorre em relação aos processos escolares e à orientação deles no sentido da autoconstruçáo humana. Idêntica necessidade acontece em relaçáo ao conhecimento e à apreensão dos fins, meios, formas de ensinar, aprender e avaliar, todos precisam ser articulados em sua totalidade e dominados de forma livre e consciente, se náo por todos, ao menos por grupos de indivíduos que possam ser multiplicadores. Náo bastam, por conseguinte, as boas doses de disposiçóes subjetivas baseadas no voluntarismo idealista para articular os processos escolares com a autoconstrução humana; antes a comunidade escolar precisa atingir determinado grau de consciência.

Na mesma caminhada, o cotidiano escolar necessita ser repensado com bastante urgência. As escolas, seja como lugar de enfado, onde professores e alunos se digladiam em meio a relaçóes muito tensas, seja onde imperam a alegria fácil, o descompromisso com as atividades educacionais, o individualismo autorreferenciado, as representaçóes idealizadas e as formas de convivências que se regem por obrigaçóes circunstanciais, historicamente reforçam a superficialidade, a ausência de seriedade, a falta de critérios etc. Ambas precisam ceder espaço a escolas diferentes e alegres na acepção de Snyders (1993). Mas a alegria da qual nos fala é cultural. Está longe de ser igual à que prevalece na sociedade do consumo e que nos leva à insaciedade compulsiva. Esta alegria é a do contentamento escolar decorrente "da convivência com a cultura cultivada" e que culmina na relação entre o estudante e os mais belos resultados atingidos pela cultura historicamente produzida: dos mais belos poemas e teoremas de ouro às descobertas prodigiosas e tecnologias inacreditáveis.

Mas, afinal, como instaurar tal centralidade na avaliação com referência à objetividade? Obviamente que nos limites desta avaliação educacional náo significa tão simplesmente abrir mão dos exames objetivos e subjetivos, até porque uns e outros constituem uma unidade indissolúvel. A síntese pretendida, isto é, a avaliação com 
centralidade na objetividade social incorre na superação dos defeitos do objetivismo e do subjetivismo, compreendendo a objetividade como objetivação da subjetividade, ou seja, como a objetividade que subordina estritamente os processos de ensino, aprendizagem e avaliação. Sua efetivação, entretanto, impóe desafios. Demanda ainda tornar-se mediadora das atividades e interatividades dos indivíduos concretos diretamente comprometidos com a autoconstrução humana.

Novamente vale insistir: os indivíduos concretos comprometidos com a autoconstrução humana, capazes de propiciar a objetividade como mediação, são os docentes dispostos a trabalhar pela instauração da sociedade emancipada, com consciência de seus deveres e dos seus conteúdos filosóficos. Isto significa estabelecer conscientemente os fins e os meios indispensáveis à sociedade emancipada. Tais fins são: a formação de pessoas/estudantes conscientes dos direitos e deveres próprios de uma sociedade democrática, com atitudes de engajamento e transformação social diante das desigualdades e das estruturas que as reproduzem. Crianças e jovens, portanto, em condiçôes de compreender que a realização pessoal envolve a realizaçáo das demais pessoas, e que a participaçáo social consciente e ativa é mister à condução das coisas públicas.

A caminhada tem início na própria consistência intelectual dos docentes, seja no que diz respeito à sua formaçáo profissional e aos conteúdos de sua disciplina, seja no sentido da formaçáo humana para a sociedade emancipada. Todos precisam ser exemplares em seus compromissos profissionais com as atividades educacionais; sempre dispostos a exames profundos e criteriosos do conhecimento e das práticas sociais, sem superficialidades e açodamentos, e com disposição criteriosa para destruir as representaçôes idealizadas.

Quanto às nossas práticas avaliativas - provas, testes, exercícios, trabalhos em grupos etc. - obviamente, também merecem ser repensadas. Não se trata de abandoná-las, mas de subordiná-las à objetividade social essencial para a construção da sociedade emancipada. Nos anos do ensino fundamental, por exemplo, é conveniente que tais práticas levem os estudantes a ter regularidade e disciplina de estudo. Gramsci (1999), a esse respeito, nos lembra que estamos lidando com crianças e adolescentes que necessitam adquirir "certos hábitos de diligência, de exatidão, de compostura até mesmo física, de concentração psíquica em determinados assuntos", que somente podem ser adquiridos por meio de disciplina e método. Tais práticas, contudo, dispensam ser utilizadas para fins classificatórios, para distinguir os melhores dos piores. É melhor que sejam usadas como meios fundamentais para o surgimento de grandes estudiosos autônomos, necessários a todas as civilizações. 
O conceito de "zona de desenvolvimento proximal" desenvolvido por Vygotsky (1993), neste caso, pode ser de grande valia. Sua utilização permite-nos dar visibilidade ao nível real de desenvolvimento dos estudantes e definir as outras mediaçóes adequadas ao seu desenvolvimento potencial. A avaliação da aprendizagem, mediada pela objetividade social, "não lida com o produto acabado, nem negligencia a dinâmica e o desenvolvimento do processo em si". Tampouco se preocupa com a realização de feedbacks para a avaliação da eficácia de programas. O que busca é a percepção e a elaboração intelectual dos estudantes, isto é, com que clareza dão origem aos conceitos, assim como para confrontá-los com o que ainda precisam apreender. As práticas avaliativas, assim, passam a ser meios de identificar os progressos realizados pelos estudantes em termos de desenvolvimento potencial, o que eles náo sabem resolver imediatamente ou somente são capazes de resolver com a ajuda de colegas e professores, indicam apenas os momentos nos quais necessitam de mediaçóes adequadas.

Em nenhum momento há a hipótese de rigor avaliativo para classificar, excluir ou formar pequenas elites de estudantes. Não, absolutamente não; isto seria um retorno às práticas tradicionais mais criticáveis, aquelas que pretendemos superar definitivamente por estarem sempre a serviço da classe dominante. A marca social da escola comprometida com a sociedade emancipada é a de preparar estudantes como homens superiores capazes de pensar, de estudar, de dirigir ou de controlar quem dirige, como Gramsci (1999) nos ensina. Com esta marca, a escola, principalmente as escolas públicas de ensino fundamental e médio, deixam de perpetuar a educaçáo para os postos de trabalho, cargos e funçóes mais inferiores da sociedade. Para tanto, vale insistir, não precisa ser triste, enfadonha ou sem ternura.

As práticas avaliativas com base no conceito de zona de desenvolvimento proximal de Vygotsky são eficientes antídotos contra as exclusões, tristezas, enfados e embrutecimentos. Elas permitem desenvolver os níveis reais dos estudantes, potencializando-os a patamares superiores de conhecimentos e abstraçóes, e levando-os a se superarem com autonomia. A todo momento, os estudantes são desafiados a novas elaborações teóricas e práticas em busca da verdade objetiva, cuja materialidade vem a ser a adequação entre a essência das coisas e sua aparência fenomênica.

\section{VERDADE E OBJETIVIDADE}

As discussóes acerca da verdade objetiva e da objetividade parecem intermináveis nas Ciências Sociais. Diferentes correntes filosóficas e metodológicas têm disputado o conhecimento objetivo da verdade. Os limites deste texto impendem-me de aprofundar a questão. Presentemente, interessa-me tão somente afirmar a necessidade de 
radicalmente superarmos o pensamento comum de nossos estudantes, que apenas capta as coisas em suas aparências. Distinguir, portanto, o mundo das aparências do mundo da realidade é o modo de captar "a coisa em si" e de formar o homem superior para a sociedade emancipada.

Kosik (1976), nesse sentido, lembra-nos ser a dialética "o pensamento crítico que se propóe a compreender 'a coisa em si' e sistematicamente se pergunta como é possível chegar à compreensão da realidade”. A dialética opóe-se aos esquemas abstratos de sistematização e às representaçóes comuns. Conduz-nos a ultrapassar o mundo da aparência, a desvendar a lei do fenômeno, o mundo do movimento visível e a captar o movimento real interno, a chegar à essência. Despreza, ainda, o mundo das representaçóes e do pensamento comum e "submete-os a um exame em que as formas reificadas do mundo objetivo e ideal se diluem, perdem a sua fixidez, naturalidade e pretensa originalidade". É somente com a dialética que podemos apreender o mundo das representaçóes e do pensamento comum como produtos da práxis social da humanidade.

$\mathrm{Na}$ escola criadora da sociedade emancipada, é preciso, portanto, haver somente uma verdade como condição de chegada à verdade objetiva. Estão, por conseguinte, descartadas as várias verdades como pretendem os relativistas, e a aceitação de que "alguns pontos de vista são relativamente mais verdadeiros que outros" (Löwy, 2007). Ora, para nossos estudantes de escolas públicas - sujeitos concretos, filhos de pais integrantes da classe dominada - é indispensável que adquiram, deliberada e conscientemente, o conhecimento objetivo da realidade, da estrutura social e da conjuntura política como condição de libertação. O ponto de vista das classes dominadas, embora não seja suficiente, é, então, o que deve guiá-los em direção à sociedade emancipada. Este ponto de vista é, apesar de sua insuficiência, "o que oferece maior possibilidade de acesso" à verdade objetiva; o ponto de vista da classe dominante, diferentemente, é pleno de imposturas e dissimulaçóes para manter o seu poder. Só as classes dominadas precisam da verdade objetiva.

As práticas avaliativas a serviço da verdade e da objetividade contribuem para o conhecimento objetivo da realidade quando, de um lado, constituem-se em meios de desenvolvimento de hábitos de diligência, de exatidáo, de compostura, de concentração, somente possíveis de serem adquiridos com disciplina e método. Ao utilizá-las dessa maneira, os professores podem ir potencializando seus estudantes até que eles compreendam a realidade concreta e ajam em prol da transformaçáo social. De outro lado, sendo mediadas pela objetividade da classe dominada, tornam-se sistematizadoras dos conhecimentos dos futuros homens superiores. 


\section{CONSIDERAÇÕES FINAIS}

Os desafios que estáo postos para a prática da avaliação e construção da escola referenciada à objetividade social são enormes, mas não impossíveis de serem vencidos. O sucesso começa a passos pequenos. Um professor que queira começar a implantar a avaliação e a preparar a escola para a sociedade emancipada jamais repete as práticas românticas do filme "A Sociedade dos Poetas Mortos". Antes, conhece a correlação de forças em sua escola e trabalha para formar uma equipe, um coletivo orgânico. É com essa equipe que avançará em seus movimentos. As aulas e exames de diferentes disciplinas, conforme os membros da equipe, passam a ser preparados com rigor teórico e metodológico, mediado pela objetividade.

Gradativamente, a equipe irá assumindo como seus os problemas efetivos da escola. A resolução deles, de igual modo, deve estar articulada organicamente com a construção da sociedade emancipada e, portanto, mediadas pela objetividade social. Nesse estágio, a superação de quaisquer manifestações de corporativismo é essencial.

A ampliação do coletivo é deveras importante. Torna-se fundamental obter a adesão e o consenso dos estudantes, porque eles serão os primeiros a criticar, refrear ou constranger os dogmatismos, as sentenças de sentido geral e o autoritarismo. Nas reunióes escolares de pais e responsáveis, ordinárias e extraordinárias, os processos de ensino, aprendizagem e avaliaçáo precisam ser expostos a todos os presentes. A organicidade da comunidade na transformação da escola é indispensável. Quando os pais e responsáveis compreenderem o valor dessas transformaçóes, serão fiéis aliados para exigir que toda a escola se reorganize, subordinada à mesma objetividade. Terão orgulho de matricular seus filhos e dependentes em uma escola que tem por objetivo transformá-los em homens superiores.

A organização de seminários intra e interturmas é outra importante etapa. Desde que sejam desenvolvidos com seriedade e boas orientaçôes, se prestam para incentivar a autonomia e a confiança dos estudantes, bem como para que possam ir fazendo as sínteses necessárias aos seus novos níveis potenciais de conhecimento.

Estes primeiros passos são simples e difíceis ao mesmo tempo. Contudo, é a persistência individual e coletiva que nos permitirá outros, mais novos e mais largos, em direçáo à sociedade em que os homens seráo livres. 


\section{REFERÊNCIAS BIBLIOGRÁFICAS}

A SOCIEDADE dos poetas mortos. Direção: 2007.

Wendy Stites. Hollywood: Touchstone Pictures, 1989.

POPHAM, W. J. Manual de avaliação: regras práticas para o avaliador educacional.

COMTE, A. Reorganizar a sociedade. Lisboa: Petrópolis: Vozes, 1978.

Guimarães Editores, 1990.

SENNET,R.ACorrosão do caráter: consequências

GRAMSCl, A. Cadernos do Cárcere. Rio de Janeiro: Civilização Brasileira, 1999. v. 2.

pessoais do trabalho no novo capitalismo. Rio de Janeiro: Record, 2007.

. Concepção dialética da história. Rio

de Janeiro: Civilização Brasileira, 1978.

SNYDERS, G. Alunos felizes. Rio de Janeiro: Paz e Terra, 1993.

KOSIK, K. Dialética do concreto. Rio de Janeiro: Paz e Terra, 1976.

LÖWY, M. As Aventuras de Karl Marx contra o TONET, I. Educação, cidadania e emancipação humana. Ijuí: Unijuí, 2005.

VYGOTSKY, L. S. Pensamento e linguagem. São barão de Münchhausen. São Paulo: Cortez, Paulo: Martins Fontes, 1993.

Recebido em: julho 2008

Aprovado para publicação em: fevereiro 2009 